\section{THE WABASH CENTER}

JOURNAL on TEACHING

\section{Reviewed By}

Bernadette McNary-Zak

Rhodes College

BOOK REVIEW

\title{
Organization and Newness: Discourses and Ecologies of Innovation in the Creative University
}

\author{
Michael A. Peters and Susanne Maria Weber, editors \\ Boston, MA: Koninklijke Brill NV Publishing, 2019 (xxxiv + 278 pages, ISBN 978-90-04- \\ 39481-0, \$119.00)
}

To what extent does the organization and structure of higher education promote and inhibit creativity? The twenty-one chapters in this book come out of a series of international conferences focused on a holistic and collaborative approach to the definition and role of the creative university $(\mathrm{x})$. The majority of participants and institutions represented are located in the European Union. Centered on the observation that education resides "at the center of the economy/creativity nexus" (vii), the book asks whether "education systems, institutions, assumptions, and habits [are] positioned and able so as to seize the opportunities and meet the challenges" (vii).

The book opens with a brief preface that frames and situates study of the creative university. A formal introduction then frames the purpose of the book, to analyze newness from the perspective of organizational education ( $\mathrm{xx}$ ), and supplies a synopsis of the content. The book is divided into two parts: chapters in part one are organized around the theme of "analyzing organization, newness, and innovation;" chapters in part two focus on the theme of "strategies and actors." An epilogue, which plays with the idea of heterotopia, closes the book. Endnotes appear at the end of each chapter; references are provided at the end of the book. Scholars of religious studies and theology will find the book of limited value; with that in mind, select chapters of possible interest representing different approaches are identified here.

The first part of the book includes the chapter, "Between Organization and the New: How Lists Are Used to Create (or Reduce) Innovation," by Fabian Brückner. The chapter shares some of the results from ongoing ethnographic research of how lists function at several social services organizations. Noting the ubiquity of the practice, the author's close study attends to the "dialectic tension between the writing down and the sorting out phases" of making a list (15), and emphasizes the cognitive dimension of list making. Another chapter, titled "Organizing a New Political Culture: Women Writers and Shifts in Meanings, Power Relations, and Social Web of Society," by Ramona Mihăilă is in the second part of the book. The author locates the contributions of Romanian women in the ninteenth century and posits the impact of her finds on operative categories and constructions of European history.

This book engages a topic of ongoing consideration in higher education. Stronger editorial oversight may have resulted in a more cohesive book, and the prevention of occasional grammatical and stylistic errors. The approach and range of topics covered enables this book to serve as a resource for those interested in organizational studies. 